\title{
BRIEF ENCOUNTERS
}

ISSN: 2514-0612

Journal homepage: http://briefencounters-journal.co.uk/BE

'Making Connections, Changing Lives': Imaginaries of Commonality and Difference in Artisanal Weaving Tourism

Author(s): Kaitlyn Rabach

Email:642520@soas.ac.uk

Source: Brief Encounters, Vol. 2 No. 1 (Jan 2018), pp. 1-12.

URL: http://briefencounters-journal.co.uk/BE/article/view/97

DOI: http://dx.doi.org/10.24134/be.v2i1.97

\section{(c) Kaitlyn Rabach}

License (open-access): This is an open-access article distributed under the terms of the Creative Commons Attribution License 4.0, which permits unrestricted use, distribution, and reproduction in any medium, provided the original work is properly cited. No warranty, express or implied, is given. Nor is any representation made that the contents will be complete or accurate or up to date. The publisher shall not be liable for any actions, claims, proceedings, demand or costs or damages whatsoever or howsoever caused arising directly or indirectly in connection with or arising out of the use of this material. 


\section{'Making Connections, Changing Lives': Imaginaries of Commonality and Difference in Artisanal Weaving Tourism}

\section{Kaitlyn Rabach}

Four years ago, while studying abroad in Ifrane, Morocco, I wrote in my travel journal:

Tomorrow my [Women and Economic Development] class is going on a weaving tour in Zawiyat. I can't wait to meet these women and finally see the positive effects of women's empowerment up close. [...] I hope I see something my mom will like; this will be the best gift to get her, it will really make an impact on these women's lives.

That following day I did buy my mother a gift: a quilt from a female artisan. To my disappointment, this artisan immediately passed her hard-earned Moroccan dirhams to her husband before returning to work. On this particular tour, since the husband communicated with our group, we were barely able to connect with the women weavers. I even published an article where I described the experience: 'When we met the women from this cooperative, their faces gleamed with pride when they showed us their work [...]. We were saddened to see many of these women give the money directly to their husbands after making the sale. Some of these quilts took months or even a year to make, but once a sale was made, most of these women did not have a say where the money went or how it was spent."1 I do not mean to suggest this is the case for every 'Women and economic development project' in the region, but during this brief encounter, I recognised the interaction of kinship systems, Moroccan political economy, and global capitalism. These complicated systems of power manifested themselves in this woman's body as she passed her earnings to her husband. As I reflect back on my 19-year-old self, and those strong feelings of shock and disapproval, I wonder what structures of power enabled me to feel the entitlement that I, a young American feminist, could somehow 'help' these women in this small Moroccan village. In that moment, I believed my purchase would somehow contribute to the 'empowerment' - a vague term in this context - of the women involved in the project. Since this encounter, I have become immersed in academic discussions regarding transnational feminisms and have started to dissect some of the power dynamics and privileges involved in these encounters. For the purpose of this article, I will reflect on my own personal experiences and analyse several different tour websites to explore the channels of power implicated in weaving tourism. This article particularly investigates what Naomi Leite has defined as the 'tension between imaginaries of commonality and difference' that accompany tourists who participate in weaving tours. ${ }^{2}$ Though searching for solidarity and connection, these tourists simultaneously retain enough separation from weavers that they continue to feel both entitled and obligated to 'help' the

\footnotetext{
1 Kaitlyn Rabach, 'A Woman In Morocco', The Observer, 5 November 2012 <http://ndsmcobserver.com/2012/11/a-woman-inmorocco/> [accessed 29 July 2017] (para. 6 of IX).

${ }^{2}$ Naomi Leite, 'Afterward: Locating Imaginaries in the Anthropology of Tourism', in Tourism Imaginaries: Anthropological Approaches, ed. by Noel B. Salazar and Nelson Graburn (New York: Berghahn, 2014), pp. 260-274 (p. 270).
} 
artisans through the power of their purchases, therefore, pushing two narratives: one of commonality and the other of difference. This tension sits within a larger framework of both the commodification of women's bodies and larger political and economic processes that (re)produce global inequalities. It often blinds tourists from witnessing the multifaceted outcomes that may result from this type of gender and development project.

\section{Narratives of Commonality}

Some scholars, most notably Dean MacCannell, argue that man's search for more authentic, purer forms of life composes the backbone of the contemporary tourism industry. However, when discussing the motivations linked with tourists visiting weaving cooperatives, desire for sociability and intimacy seems more fitting. ${ }^{3}$ These terms, sociability and intimacy, may be defined differently depending on the context, but at the most basic level mean 'sharing something, communicating in some recognisable manner'. ${ }^{4}$ In this article, I refer to intimacy as a connection made in amicable, not sexual, terms. Intimate encounters could mean sparking a friendship, sharing laughter, essentially, having some sort of warm connection or encounter with others. Julia Harrison argues some travel enthusiasts 'seek intimacy through worldliness $[. .$.$] to find some sort of intimate, if temporary, bond with broader humanity. { }^{5}$ This motivation to form connections across difference shapes the imaginaries or 'meaning-making devices' derived from the representational tools and personal imaginings surrounding tourists who visit weaving cooperatives. ${ }^{6}$ The construction of these imaginings occur before, during, and after the trip, and may consist of a variety of mediums, such as tour websites, blogs, brochures, and tourists' tales. Essentially, these may be constructed in different ways, but they become embedded in the discourse surrounding certain tours. These discourses then circulate and shape the experience of the tourist before a trip takes place. Even as tourists travel, specific narratives shape their experience and continue to shape the way they describe their trip upon return. Edward Bruner, an anthropologist studying narratives that underpin touristic encounters, splits tourist narratives into three phrases: pre-tour, tour, and post-tour.?

'Weaving' - the very action of interlacing threads and fabric — is broadened to include the interconnecting of people, places, and ideas by cooperative marketing initiatives. To market a world of togetherness and connection, organisations that host tours strategically name themselves. For example, one organisation offering tours in Oaxaca, Mexico is named 'Weaving the World'. ${ }^{8}$ Another, 'Exclusive

\footnotetext{
${ }^{3}$ See: Dean MacCannell, The Tourist: A New Theory of the Leisure Class (Berkeley: University of California Press, 1999).

${ }^{4}$ Julia Harrison, Being a Tourist: Finding Meaning in Pleasure Travel (Vancouver: UBC Press, 2007), p. 48.

${ }^{5}$ Ibid., p. 51.

${ }^{6}$ Noel B. Salazar and Nelson H. Graburn, 'Introduction: Toward an Anthropology of Tourism Imaginaries', in Tourism Imaginaries: Anthropological Approaches, ed. by Noel B. Salazar and Nelson Graburn (New York and Oxford: Berghahn, 2014), pp. 1-20 (p. 1).

${ }^{7}$ Edward M. Bruner, Culture on Tour: Ethnographies of Travel (Chicago: University of Chicago Press, 2005), p. 19.

${ }^{8}$ Weaving the World Ltd, Weaving the World: Textile and Weaving Tour, Oaxaca, Mexico (United Kingdom: 2016) <http://www. weavingtheworld.co.uk/> [accessed 27 December 2016].
} 
Journeys', markets their tour as a 'journey where life-long friendships are formed'. ' Commercialising tourists' desires to connect across certain boundaries, weaving cooperatives create narratives around themes of global solidarity and intimate connections. These pre-tour narratives, to use Edward Bruner's phrase, contribute to tourists' preconceptions about both the destination, and the people they will interact with while on the weaving tour. ${ }^{10}$ Rather than emphasise the unique qualities of textiles and techniques specific to a region, organisations offer testimonies that say the success of the tours 'wasn't just about the textiles...it was the people.'11 These companies understand that their market includes tourists who are searching for the 'story' behind the product. It is not about the purchase itself, but about the connection and interaction with the 'story' or artisan behind the product. ${ }^{12}$

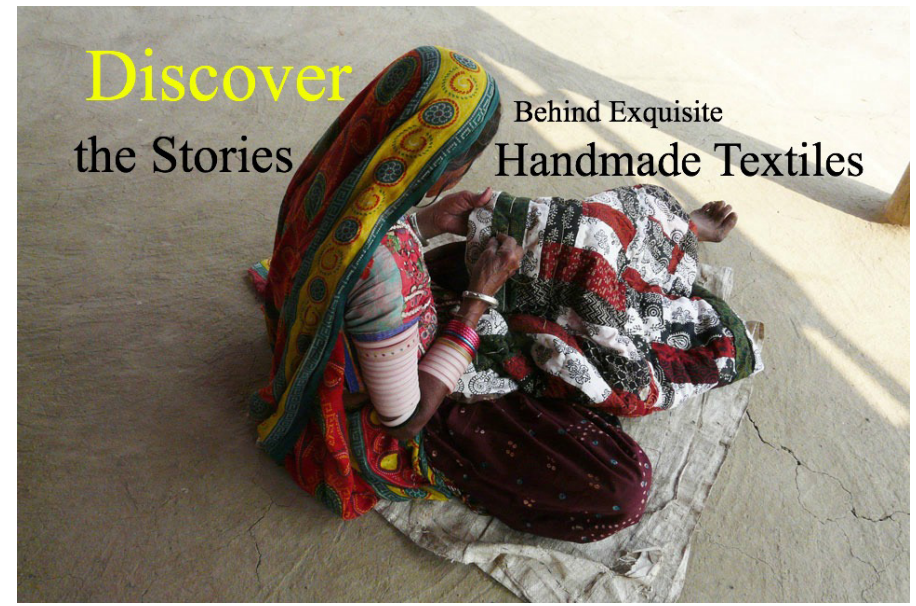

\section{Figure 1. Go Beyond the Product}

'ClothRoads: A Global Textile Marketplace' advertises their tours as an opportunity to go beyond the product and connect with the stories of the artisans. Image courtesy of ClothRoads < $<$ https://www.clothroads.com/> [accessed July 29 2017].

The emphasis on global solidarity, friendship, and connection often continues in tourists' posttour narratives or travel tales. Tourists often 'reshape' and 'personalise' pre-tour narratives to create a 'coherent narrative' about their recent trip. ${ }^{13}$ Mostly female tour participants continue to reference ideas of connection even after returning from the tour, translating pre-tour narratives into their posttour tales. Some, like an American tourist who recently returned from a weaving tour in Rakhine State, Myanmar, referred to artisans as her 'creative sisters' and 'lifelong friends'. ${ }^{14}$ The term 'sister' - a kinship term - implies a shared connection and history. Words like sister and friend add imaginaries of global kinship and solidarity being achieved through access to these weaving cooperatives. Intimacy is achieved through meeting and working with female artisans. However brief, this connection has a lasting impact

\footnotetext{
9 Lesley Robin, 'Tours', Exclusive Journeys with Lesley Robin <http://www.exclusivejourneys.com/tours/> [accessed 27 December 2016].

${ }^{10}$ Bruner, p. 19.

11 Andean Textile Arts, Making Connections, Changing Lives (7 June 2013) < http://andeantextilearts.org/blog/making connections_changing_lives.en> [accessed 27 December 2016] (para. 3 of V).

${ }_{12}$ ClothRoads, ClothRoads: A Global Textile Marketplace (2016) <https://www.clothroads.com/> [accessed 29 July 2017] (para. 1 of III).

${ }^{13}$ Bruner, p. 22.

${ }^{14}$ Anonymous Interviewee, Interviewed by Kaitlyn Rabach, November 132016.
} 
on the tourists involved. Limitations to such intimacy, however, do exist, and contradictions in narratives, both pre-tour and post-tour, may oppose one another.

\section{Narratives of difference}

Weaving cooperatives that are based within a system of gender and development market tours as a way to participate in 'women's empowerment'. Like the industry of voluntourism - a type of tourism where travel is combined with voluntary work - weaving tours rest on 'the imaginaries of the exotic other and basic unity of humankind'. 15 Those participating in weavings tours simultaneously emphasise their connection with artisans, while also highlighting their desire to positively impact the lives of these women who are part of a group different from them that they perceive as in need of help. One weaving participant actually titled her blog post 'Making Connections, Changing Lives', which illustrated the nexus relating imaginaries of intimacy and difference in just four words. Participants search for intimate encounters, but in order to fulfil an ulterior purpose for attending the cooperative - to make a difference in these women's lives - tourists must not completely blur the line between 'us' and 'them'.16

This is where Coralynn Davis' concept of 'feminist tourist' - a traveller who carries a sense of ethical and political responsibility with their travels and purchases - may be used to explore a second set of tourist imaginaries involved in those visiting weaving cooperatives. ${ }^{17}$ This set of imaginaries involves narratives built upon helping third-world women, conceived of as a universal group who are 'poor, illiterate and oppressed' to move toward empowerment. ${ }^{18}$ The feminist tourist, like those who participate in weaving tours, believes her purchases serve as a feminist intervention in women's worldwide oppression, as well as a tool to understand her own self-identification. ${ }^{19}$ For instance, one cooperative offers tourists a chance to 'partner with women on their journey out of poverty and toward empowerment and selfsufficiency'. ${ }^{20}$ This marketing reinforces the perception that third-world women are in need of assistance to help them move toward empowerment and out of their impoverished lifestyle.

Upon her return from Guatemala, one American woman described her trip, in a testimonial for the tour's website, as 'at its core being about connection' and further noted that 'inherent [in this tour] is the belief that I too can make a difference in helping repair the world'. ${ }^{21}$ Her trip was comprised of two main highlights: making connections, and helping others. Two different narratives combined in a reflection on one trip. Her purchases and connections during a tour in Guatemala allowed her to contribute in some small part towards 'helping repair the world'. The artisans she connected with and subsequently 'helped'

\footnotetext{
${ }^{15}$ Leite, p. 270.

${ }^{16}$ Andean Textile Arts, (para. 1 of $\mathrm{V}$ ).

${ }^{17}$ Coralynn Davis, 'The Politics of Purchasing Power: Feminist Tourism and Women's Development in Nepal', Michigan Feminist Studies, 12 (1997), 26-43 (p. 26).

18 Ibid., p. 34.

19 lbid., p. 33.

${ }^{20}$ Mayan Hands, 'About us', Mayan Hands (2016) <http://www. mayanhands.org> [accessed 27 December 2016] (para. 3 of V).

${ }^{21}$ Hetty Friedman Designs, 'Crafts for Cause Testimonials', Hetty Friedman Designs (2016) < http://www.hettyfriedmandesigns. com/testimonials> [accessed 26 December 2016].
} 
were perceived to be a part or piece of this larger project. As intimate as her connection may have been, her post-tour narrative includes a clear 'me' vs. 'them' distinction. Another woman said that before she left to return home, she put a cloth close to her face to 'inhale all the goodness from this priceless experience'. ${ }^{22}$ This 'goodness' refers to her memories of warm laughter with female weavers and her role in sustaining the local economy for these women. Testimonies like this, which are common in weaving participants' post-tour narratives, perpetuate both imaginaries of commonality and difference among those who participate in weaving tours.

Another way post-tour narratives emphasise difference between artisans and tourists is by contributing to the imaginary that third-world women, often marketed as indigenous, are somehow closer to earth. ${ }^{23}$ Although this sort of narrative has long been debated within Western thought; it seems to be emphasised even more when categories of 'woman' and 'indigeneity' are combined. ${ }^{24}$ Accentuating images where 'women sit on the ground weaving with the loom attached to the bodies' or 'stand bent forward as they work at the adobe stove' all emphasise 'women's closeness to earth'. ${ }^{25}$ For instance, Mayan Hands, an organisation offering tours in Guatemala, highlights how Mayan women 'love to inscribe their cloth with symbols of the earth's sacredness'. ${ }^{26}$ This imaginary, of women weavers in the global south, as being somehow 'closer to earth' is perpetuated in post-tour narratives when tourists comment on weavers being close to the ground or using only natural remedies to dye their products. Still searching for connection, this attention to subtle differences, like that of a woman weaving close to the ground without a chair or bench, may remind the tourist of the line between artisan and visitor. In some ways, this imaginary of difference may reinforce the barrier between women of the global north and south.

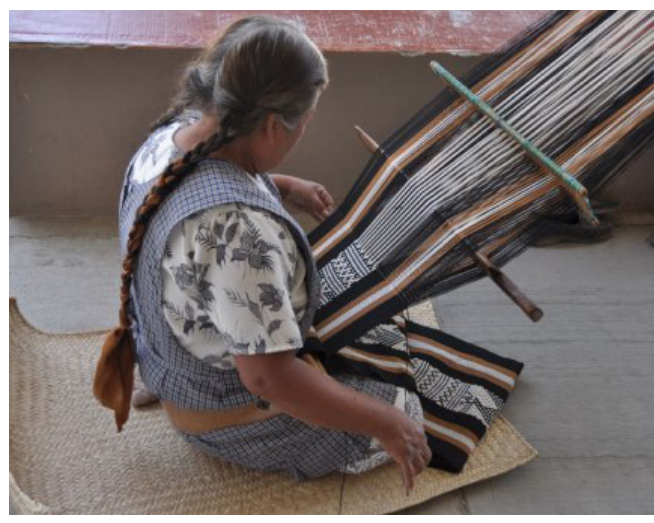

\section{Figure 2. Close to Earth}

Published on the Cloth Roads website, this image displays a female artisan working close to the ground, a point many tourists discuss in their post-tour tales. Image courtesy of Cloth Roads <https://www.clothroads.com/ $>$ [accessed July 29 2017].

\footnotetext{
${ }^{22}$ Catherine Mack, 'Marrakech Holidays: Meet the Women', Guardian, 25 Jan. 2009 <https://www.theguardian.com/travel/2009/ jan/25/women-travel-morocco-weaving-women> [accessed 2 January 2017] (para. 18 of XIX).

${ }^{23}$ Annelou Ypeij, 'The Intersection of Gender and Ethnic Identities in Cuzco-Machu Picchu Tourism Industry', Latin American Perspectives, 39 (2012), 17-35 (p. 30).

${ }^{24}$ See Women, Culture, and Society, ed. by Louise Lamphere and Michelle Rosaldo (Stanford: Stanford University Press, 1974).

${ }^{25}$ Ypeij, p. 30.

${ }^{26}$ Mayan Hands, 'About us' (para. 1 of V).
} 


\section{Uneven Processes}

This tension between imaginaries of commonality and difference sits within a larger framework of uneven global processes of development. These tours are situated in a historical time where women's bodies have become 'the locus of economic development as human capital investments in 'potential' productivity'. ${ }^{27}$ Women's development, then, becomes more than a moral imperative, but actually becomes financially productive. Women's bodies, like the female artisans selling their weaving processes, have become a means of capital investment. For instance, in an interview I conducted with International Monetary Fund (IMF) Director Madame Christine Lagarde in 2014, she emphasised the need to sidestep moral commitments when referring to women's development and instead

[D]emonstrate [the positive effects of women's development] by using facts, numbers, and evidence. [...] If you, for instance, assume that Japanese women enter the Japanese market in the same proportion as men, and participate in the economy in the same proportion, the overall economy could go up, I think it was seven percentage points, over a period of time. That is what I call a no brainer. ${ }^{28}$

This no-brainer, though, referring to women's development, is problematised when terms and limits are created in the global north and imposed on the global south.

The same is true for first-world tourists who purchase artifacts from Nepali, Guatemalan and Mayan women. These tourists, searching to form connections and make a difference, are actually participating in an 'international exchange of power, money and meaning', though often fail to recognise their participation in tours as such. ${ }^{29}$ As Davis argues, when using kinship terms like 'sister' or Western words like 'empowerment' these feminist tourists do not necessarily understand these terms in the context of the space they are visiting or working. ${ }^{30}$ Following a similar parallel to Western feminists at the famous 1995 Beijing Conference on Women, visitors of weaving tours often see themselves as 'enlightened and liberated subjects with the answers to the problems of women in non-Western cultures'. ${ }^{31}$

A feeling of obligation frequently accompanies this so-called enlightenment. In that same interview, Madame Lagarde said the very basis of womanhood is dependent on 'being satisfied that you are helping other people and are giving love to other people., ${ }^{32}$ This rhetoric around the connection between womanhood and helping others is highlighted throughout much of the weaving tour websites and post-tour testimonies. Visitors emphasise their duty to really connect with locals in order to help

\footnotetext{
${ }^{27}$ Heather Switzer, '(Post)Feminist Development Fables: The Girl Effect and the production of sexual subjects', Feminist Theory, 14 (2013), 345-360 (p. 347).

${ }^{28}$ Kaitlyn Rabach, 'Gen Y Report from the 2014 Women in the World Summit', The Huffington Post, 8 April $2014<$ http://www. huffingtonpost.com/kaitlyn-rabach/gen-y-report-from-the-201_b_5111364.html> [accessed 27 December 2016] (para. 10 of $\mathrm{XXI}$ ).

${ }^{29}$ Davis, p. 27.

${ }^{30}$ Ibid., p. 35.

${ }^{31}$ Aihwa Ong, 'Strategic Sisterhood or Sisters in Solidarity? Questions of Communitarianism and Citizenship in Asia', Indiana Journal of Global Legal Studies, 4 (1996), 107-135 (p. 112).

${ }^{32}$ Rabach, (para. 6 of $\mathrm{XXI}$ ).
} 
improve artisans' 'self-esteem', and believe their purchases serve as a political intervention toward women's empowerment. ${ }^{33}$ Owing to the fact that much of the Western world is run on individualistic terms, post-tour narratives emphasise female artisans' journey toward 'self-sufficiency', rather than understanding the cooperative's goals in a more community-based way. In many countries where weaving tours take place, 'women's emancipation is never just about individual rights but fundamentally about culture, community, and the nation'. ${ }^{34}$
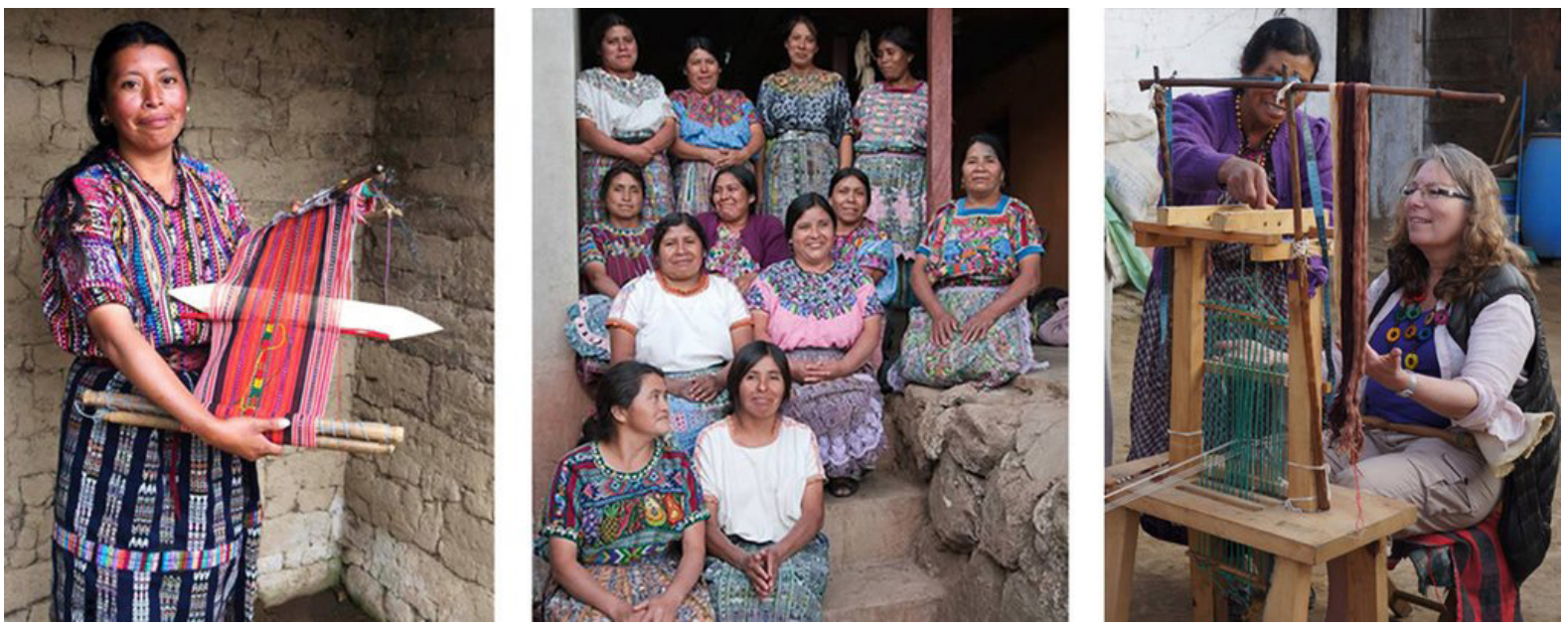

Figure 3. Smiling Faces

Featured under the 'tour' subheading of the Mayan Hands website, this series of photos portray a story of proud female artisans featuring their products, smiling faces, and teaching skills. Image courtesy of Mayan Hands <https://www.mayanhands.org/pages/tours> [accessed July 252017 ].

Problematising an imposition of Western values on women weavers becomes more difficult when tourists participating in these tours share contradicting imaginaries of both commonality and difference. Tourists, functioning within narratives like 'weaving the world' and 'making connections', work from the assumption that the world is 'without boundaries'. ${ }^{35}$ This sort of notion fits with the imaginary of commonalities because in these metaphors there are no borders to interfere with the weaving of different cultures, people, and spaces. However, in this framework, the weaving of difference actually incorporates threading Western values of individualism, feminism, and human rights with what tourists perceive as more backward or 'underdeveloped' notions of womanhood and living. ${ }^{36}$

\section{Imaginaries vs. Reality}

One of the problems associated with the contradictory imaginaries around weaving tours is the unifying perspective that a woman's participation in a cooperative automatically assumes a path toward freedom and empowerment. Whether analysed from an angle of commonality or difference, this notion is

\footnotetext{
${ }^{33}$ Mayan Hands, 'About us' (para. 4 of V).

${ }^{34}$ Ong, p. 111.

${ }^{35}$ Caren Kaplan, 'A World without Boundaries; The Body Shop's Trans/National Geographies', Social Text, 43 (1995), 45-66 (p. 45).

${ }^{36}$ Davis, p. 34
} 
articulated in marketing campaigns and post-tour narratives. One website ensures that participating in a weaving tour will not only make these women's dreams for 'a better life come true', but will also allow for a 'very important change for the next generation' where artisans are already talking of their 'children becoming lawyers or doctors or some other kind of professional. ${ }^{37}$ This type of narrative, where women's empowerment automatically assumes a better life, is inconsistent with the breadth of ethnographies several anthropologists have conducted on weaving tourism. In fact, most of these researchers actively argue against such a one-sided story. ${ }^{38}$ Rather, they encourage a broader understanding of the interrelations among actors involved in weaving tourism, including tourists, marketers, brokers, guides and state agencies.

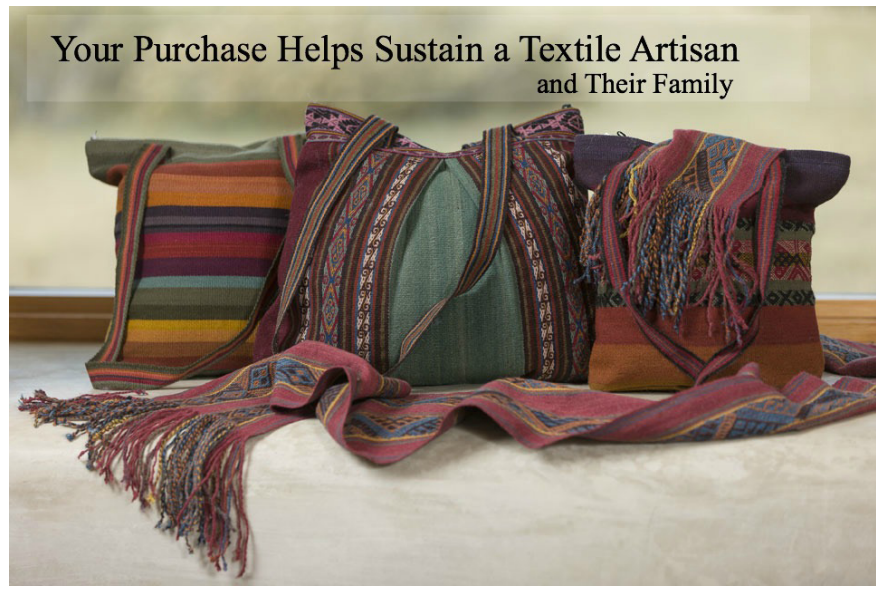

\section{Figure 4. Empowering Families}

Featured on the home page of the Cloth Roads website, this image contributes to a discourse that emphasizes the inextricable relationship between women's empowerment and the empowerment of entire families and communities. Image courtesy of ClothRoads. [accessed July 29 2017].

For instance, while studying the effects of gender and weaving tours in Cuzco-Machu Picchu region of Peru, Annelou Ypeij found that a woman involved in weaving cooperative may have increased flexibility within the dynamics of her individual household or partnership, while simultaneously yielding power to male tour guides who control her flow of consumers, and ultimately, her income. ${ }^{39}$ The woman may have gained a greater degree of respect within the private sphere - in some cases the husbands now work for their wives - but the gendered relationship between the weaver and guide is unequal. $\mathrm{A}$ weaver's standing with guides may control her own and her family's entire livelihood relating to income and work.

Development projects may have unintended consequences, both positive and negative. The lack of understanding surrounding these multifaceted consequences in the realm of family life, community

\footnotetext{
${ }^{37}$ Mayan Hands, 'About us' (para. 5 of V).

${ }^{38}$ See Jill Forshee, Between the Folds (Honolulu: University of Hawai'i Press, 2001); Carol Hendrickson, 'Women, Weaving, and Education in Maya Revitalization', in Maya Cultural Activism in Guatemala, ed. by Edward F. Fischer and R. McKenna Brown (Austin: University of Texas Press, 2001), pp. 157-165; Walter E. Little, Mayas in the Marketplace: Tourism Globalization and Cultural Identity (Austin: University of Texas Press, 2004), pp. 64-177; Ypeij, pp. 1-227.

${ }^{39}$ Ypeij, pp. 17-35.
} 
projects and economics is a result of the telling of only a single story. For instance, part of the shock and disappointment I felt after visiting the cooperative in Zawiyat may have resulted from my expectation that such projects automatically lead to extra freedoms for women. The action of the woman passing her earnings to her husband contradicted my own imaginaries surrounding gender and development projects, imaginaries constructed from post-tour narratives and marketing campaigns that assume that 'empowering' a woman automatically results in a shift of power dynamics. In that moment, I witnessed the disconnection between the tourism imaginary and reality.

\section{Conclusion}

While exploring the complicated systems of power involved in weaving tours, imaginaries of commonality and difference ring throughout marketing schemes and tourist reflections, conceptualised within the framework of Bruner's pre-tour and post-tour narratives. Tourists who participate in weaving tours strive for an intimate connection, like Harrison describes in her work, while simultaneously sharing imaginaries of difference among 'third-world' women. Often, testimonies of weaving tours begin with a story about connecting with 'friends' from across the world and end with a few words on how gratifying the experience of 'helping' these women were. Weaving cooperatives work to form just enough connection that tourists feel they have some stake in an artisan's journey toward empowerment, but continue to emphasise small differences, like a non-Western woman's closeness to earth, to ensure the line between host and guest is not completely blurred.

This desire to both connect and 'empower' women across the global south fits into larger narratives surrounding gender and development, as exhibited by Lagarde's take on the financial successes of encouraging women to enter the workforce. Imaginaries involved with these weaving tours can be problematised when Western values of individuality and empowerment are imposed on development organisations and weaving cooperatives. This imposition may lead to a disconnect between the tourists who hold certain views on women's advancement, and the female artisans who understand such terms in a more community-based context. This disconnect may also occur when tourists fail to recognise their presence as part of a series of larger global processes surrounding power dynamics of the global north and south. The issue becomes more severe when marketing agencies and post-tour narratives fail to understand women's empowerment and development in an all-encompassing manner. One-sided stories that assume Western-feminist intervention is the absolute solution to shifting power dynamics within a woman's world ignore the various actors involved in weaving cooperatives and tourism in general.

This article only begins to tackle some of the tensions that may occur 'between imaginaries of commonality and difference' and only within a context of weaving tourism. Most tour websites and marketing campaigns focus on the experience of the tourists and contain rather limited testimonies from female artisans themselves. ${ }^{40}$ This type of rhetoric, one where tourists simultaneously seek

\footnotetext{
${ }^{40}$ Leite, p. 270.
} 
connection and promote difference, may be found in other arenas within tourism, such as voluntourism, ecotourism, and community-based tourism. The case of weaving tourism, however, is unique in the fact that it is highly gendered and both hosts and guests tend to be women. Much of the recent literatures surrounding tourism imaginaries emphasise encounters of 'difference'. This small case study, though, attempts to show that both narratives of commonality and difference may be motivating factors in a tourists' decision to participate in a certain type of tour, such as a weaving tour. These tour participants are searching not only for a sort of intimate connection, as Harrison argues, but also a form of solidarity. Though their encounters with weaving artisans may be brief, they are certainly not shallow. Rather, these tourists emphasise the lasting impact they hope these encounters will have in the lives of the artisans, as well as their own. Artisans are not 'friends' and 'sisters' one minute and 'exotic others' in need of 'help' the next; rather, they are both of these things at the same time. Moving forward with the conceptualisation of tourism imaginaries, anthropologists must work to better understand these sort of simultaneous contradictions, especially when theorising imaginaries and narratives around global solidarity, gender identity, and womanly obligations within touristic encounters. 


\section{Bibliography}

Andean Textile Arts, Making Connections, Changing Lives (7 June 2013) <http://andeantextilearts.org/ blog/making_connections_changing_lives.en> [accessed 27 December 2016]

Bruner, Edward M., Culture on Tour: Ethnographies of Travel (Chicago: University of Chicago Press, 2005)

ClothRoads, ClothRoads: A Global Textile Marketplace, (2016) <https://www.clothroads.com/> [accessed 29 July 2017]

Davis, Coralynn, 'The Politics of Purchasing Power: Feminist Tourism and Women's Development in Nepal', Michigan Feminist Studies, 12 (1997), 26-43

Forshee, Jill, Between the Folds (Honolulu: University of Hawai'i Press, 2001)

Harrison, Julia, Being a Tourist: Finding Meaning in Pleasure Travel (Vancouver: UBC Press, 2007)

Hendrickson, Carol, 'Women, Weaving, and Education in Maya Revitalization', in Maya Cultural Activism in Guatemala, ed. by Edward F. Fischer and R. McKenna Brown (Austin: University of Texas Press, 2001)

Hetty Friedman Designs, 'Crafts for Cause Testimonials', Hetty Friedman Designs (2016) <http://www. hettyfriedmandesigns.com/testimonials> [accessed 26 December 2017]

Kaplan, Caren, 'A World without Boundaries; The Body Shop's Trans/National Geographies', Social Text, 43 (1995), 45-66

Lamphere, Louise and Michelle Rosaldo eds., Women, Culture, and Society (Stanford: Stanford University Press, 1974)

Leite, Naomi, 'Afterward: Locating Imaginaries in the Anthropology of Tourism', in Tourism Imaginaries: Anthropological Approaches, ed. by Noel B. Salazar and Nelson Graburn (New York and Oxford: Berghahn, 2014), pp. 260-274

Little, Walter E., Mayas in the Marketplace: Tourism Globalization and Cultural Identity (Austin: University of Texas Press, 2004)

MacCannell, Dean, The Tourist: A New Theory of the Leisure Class (Berkeley: University of California Press, 1999)

Mack, Catherine, 'Marrakech Holidays: Meet the Women', Guardian, 25 Jan. 2009 $<$ https://www.theguardian.com/travel/2009/jan/25/women-travelmorocco-weaving-women> [accessed 2 January 2017]

Mayan Hands, 'About us', Mayan Hands (2016) <http://www.mayanhands.org> [accessed 27 December 2016]

Ong, Aihwa, 'Strategic Sisterhood or Sisters in Solidarity? Questions of Communitarianism and Citizenship in Asia', Indiana Journal of Global Legal Studies, 4 (1996), 107-135

Rabach, Kaitlyn, 'A Woman in Morocco', Observer, 5 Nov. $2012<$ http://ndsmcobserver.com/2012/11/awoman-in-morocco/> [accessed 29 July 2017]

Rabach, Kaitlyn, "Gen Y Report From the 2014 Women in the World Summit', The Huffington Post, 8 Apr. 2014 <http://www.huffingtonpost.com/kaitlyn-rabach/gen-y-report-from-the-201_b_5111364. html> [accessed 27 December 2016] 
Robin, Lesley, 'Tours', Exclusive Journeys with Lesley Robin (2010-2016) <http://www.exclusivejourneys. com/tours/> [accessed 27 December 2016]

Salazar, Noel B. and Nelson H. Graburn, 'Introduction: Toward an Anthropology of Tourism Imaginaries', in Tourism Imaginaries: Anthropological Approaches, ed. by Noel B. Salazar and Nelson Graburn (New York and Oxford: Berghahn, 2014), pp. 1-20

Switzer, Heather, '(Post)Feminist Development Fables: The Girl Effect and the production of sexual subjects', Feminist Theory, 14 (2013), 345-360 <https://doi.org/10.1177/1464700113499855>

Weaving the World Ltd, Weaving the World: Textile and Weaving Tour, Oaxaca, Mexico (United Kingdom: 2016) <http://www.weavingtheworld.co.uk/> [accessed 27 December 2016]

Ypeij, Annelou, 'The Intersection of Gender and Ethnic Identities in Cuzco-Machu Picchu Tourism Industry', Latin American Perspectives, 39 (2012), 17-35 <https://doi.org/10.1177/0094582X12454591>

Zorn, Elaine, Weaving a Future: Tourism, Cloth, and Culture on an Andean Island (lowa City: University of lowa Press, 2004) 